\title{
El espejo en La Rambla paralela (2002) de Fernando Vallejo*
}

Fecha de recepción: 24 de abril de 2017

Fecha de aprobación: 29 de junio de 2017

\section{Resumen}

Las novelas del colombiano Fernando Vallejo se caracterizan por ser propuestas autoficcionales escritas en primera persona y desde el exilio. Dentro de ellas sobresale La Rambla paralela (2002) por ser una novela en la que el narrador tradicional de Vallejo, uno en primera persona, configura un biógrafo que escribe, desde la tercera persona, el viaje a Barcelona y la muerte del narrador. El interés de este artículo es evaluar cómo el desdoblamiento del narrador-autor en la figura del biógrafo, le permite al primero hacer de la novela un espejo por medio del cual evalúa sus rasgos estilísticos.

Palabras clave: Fernando Vallejo, La Rambla paralela , autoficción, metaficción, literatura narcisista, narrativa especular.

\section{Mario Alberto Domínguez Torres}

Doctor en Literatura de la Universidad de los Andes ma.dominguez11@uniandes.edu. co

* Este artículo de reflexión es producto de mi investigación doctoral «El espacio en Fernando Vallejo. Una aproximación literaria al universo diegético, rural y urbano de su narrativa autoficcional».

Citar: Domínguez Torres, M. A. (enero-junio de 2017). El espejo en La Rambla paralela (2002) de Fernando Vallejo. La Palabra, (30), 53 - 68. doi: https://doi. org/10.19053/01218530.n30.2017.6208 


\section{la palabra}

\section{The Mirror in La Rambla paralela [My Parallel Deaths] (2002) by Fernando Vallejo}

\section{Abstract}

The novels of the Colombian author Fernando Vallejo (1942) are auto-fictional proposals written in the first person and from a place of exile. Within them, La Rambla paralela (2002) stands out for being a novel in which the traditional first person narrator of Vallejo, creates a biographer who writes, from the third person, about the trip to Barcelona and the death of the narrator. The aim of this article is to evaluate how the unfolding of the narrator-author in the figure of the biographer allows the first to make the novel into a mirror through which he evaluates his stylistic attributes.

Keywords: Fernando Vallejo, La rambla paralela [My Parallel Deaths], Autofiction, Metafiction, Narcissistic narrative, Specular narrative.

\section{Le miroir dans La Rambla paralela (2002) de Fernando Vallejo}

\section{Résumé}

Les romans de l'écrivain colombien Fernando Vallejo (1942) se caractérisent par une écriture d'autofiction en première personne et en exil. La rambla paralela se distingue parce que le narrateur traditionnel de Vallejo en première personne, construit un biographe qui écrit en troisième personne le voyage à Barcelone et la mort du narrateur. Dans cet article nous analyserons dans quelle mesure le dédoublement du narrateur-auteur dans la figure du biographe permet au narrateur-auteur de constituer un miroir dans le roman qui lui permet d'évaluer ses traits stylistiques.

Mots-clés: Fernando Vallejo, La Rambla paralela, Autofiction, Métafiction, Littérature narcissique, Narration spéculaire. 
Por ese mismo tiempo le dio por escribir de él en tercera persona, como si un pudor repentino lo hubiera apresado, como si de repente le hubiera dado vergüenza del pronombre yo, y se hubiera puesto la máscara de un él que no podía ser otro que él. Eran reflexiones muy intimas y quizás con la tercera persona lograba la distancia necesaria para no sentirse en un impúdico confesionario.

Héctor Abad Faciolince, Basura

Las doce novelas autoficcionales hasta el momento publicadas por el colombiano Fernando Vallejo (1942- ) se enfocan en los recuerdos, percepciones y experiencias de vida de su narrador homónimo ${ }^{1}$, se agrupan en tres ciclos narrativos ${ }^{2}$ y se configuran a partir de una poética del yo, entendida esta de acuerdo con los términos que emplea Tzvetan Todorov en su Poética estructuralista (1977): la poética «apunta al conocimiento de las leyes generales que presiden el nacimiento de cada obra» e indaga por las cualidades del discurso literario (1991, p. 30) . $^{3}$. En La Virgen de los Sicarios se consolida una ley narrativa que fácilmente se extiende a la obra general del antioqueño, cuando el narrador se afirma como una voz en primera persona:

Dicen los sociólogos que los sicarios le piden a María Auxiliadora que no les vaya a fallar, que les afine la puntería cuando disparen y que les salga bien el negocio. ¿Y cómo lo supieron? ¿Acaso son Dostoievsky o Dios padre para meterse en la mente de otros? ¡No sabe uno lo que uno está pensando va a saber lo que piensan los demás! (Vallejo, 2002, pp. 15-16).

A través de la negación, se manifiesta un modo singular de enunciar el mundo: no ser Dostoievsky ni Dios; es decir, no ser un narrador que está en todas partes o que lo sabe todo y que, por ello, tiene la potestad de ingresar a las mentes de sus criaturas literarias. En oposición a esto, las propiedades del discurso vallejiano parten de una ley general - un Yo con un punto de vista restringido que refiere su autoficción desde su subjetividad-que cualifica su discurso: nombrar el mundo desde su ex-

1 A lo largo de las doce novelas es común que el narrador-autor-protagonista refiera su nombre y sus apellidos de manera indirecta y fragmentaria. Por ejemplo, en Los días azules Lía, la madre del narrador, le da órdenes: «"Fernando: hacé esto, hacé lo otro". Y yo: "Darío: hacé esto, hacé lo otro"» (2013c, p. 84). En El fuego secreto, al ver unos nombres apuntados en la libreta de amantes de Chucho Lopera, el narrador comenta: «Entre los ajenos, vacíos nombres de la libreta, que por un instante tuve en las manos, fueron pasando dispersos -Fernando Villa, Juan de Dios Vallejo- mi nombre y mi apellido» (2013b, p. 11). En La Virgen de los Sicarios cuando asesinan a Alexis, éste, antes de recibir el impacto, salva de la muerte al narrador y lo llama Fernando (2002, pp. 78-79). En Los caminos a Roma, El desbarrancadero y Casablanca la bella refiere su apellido materno (2009d, p. 154; 2008a, pp. 29-30, 32-33, 157; y 2013a, pp. 53, 58 y 59). En Mi hermano el alcalde, El don de la vida y iLlegaron! refiere el nombre de su padre, Aníbal Vallejo Álvarez, o de su madre, Lía Rendón (2008b, p. 46; 2010 , pp. 29,54 ; y 2015 , pp. $25,98,105,108,113,114,123)$.

2 Cada ciclo narrativo presenta distintos momentos de escritura del Yo y se define por la particular forma de empleo de los mecanismos de enunciación. La pentalogía de El río del tiempo, primer ciclo narrativo (1985-1993), está compuesta por las primeras cinco novelas de Vallejo — Los días azules (1985), El fuego secreto (1987), Los caminos a Roma (1988), Años de indulgencia (1989) y Entre fantasmas (1993)_; en ella se presenta una escritura autobiográfica y signada por la evocación voluntaria del pasado del narrador en el que se construye a Santa Anita, la hacienda familiar, de manera ambivalente (paraíso-infierno) y se consolida a Medellín como el principal referente físico y emotivo. El segundo ciclo narrativo (1994-2004) lo conforman las siguientes cuatro novelas: La Virgen de los sicarios (1994), El desbarrancadero (2001), La Rambla paralela (2002) y Mi hermano el alcalde (2004). Estas novelas no continúan la línea cronológica del ciclo previo, refieren eventos aislados e inconexos y se caracterizan por el regreso físico del narrador a los espacios rurales y urbanos de la pentalogía, motivos por los que la memoria voluntaria no juega un papel importante. Finalmente, el tercer ciclo narrativo (2010-2015) está constituido por las tres últimas novelas: El don de la vida (2010), Casablanca la bella (2013) y iLlegaron! (2015); en ellas hay un tránsito de una voz monológica al diálogo y el narrador adquiere una postura estática que le permite reflexionar sobre el mundo que contempla o recuerda.

3 Según Todorov, «[e]l objeto de la poética no es la obra literaria misma: lo que ella interroga son las propiedades del discurso literario. Entonces toda obra sólo es considerada como la manifestación de una estructura abstracta mucho más general, de la cual ella es meramente una de las realizaciones posibles» (1991, pp. 30-31). 
periencia de vida, bien porque es testigo de lo acontecido, bien porque lo recuerda.

En sus ensayos «El gran diálogo del Quijote» (2005) y «Un siglo de soledad» $(1998)^{4}$, Vallejo reafirma dicha postura al despotricar de la omnipresencia y la omnisciencia de los narradores de Gabriel García Márquez, Fiódor Dostoyevski o Gustave Flaubert, y encumbrar las limitaciones y subjetividades de su propio narrador. Vallejo argumenta que El Quijote, contrario a lo expuesto por la crítica, es una novela en primera persona, debido a ese «de cuyo nombre no quiero acordarme» de su inicio. Para él, El Quijote parodia cuanta cosa encuentra (la novela pastoril, la de caballería, la Santa Hermandad, el Santo Oficio), y la novela misma no es la excepción:

[...] se burla de sí mismo y del género de la novela de tercera persona a la que aparentemente pertenece $y$ del narrador omnisciente, ese pobre hijo de vecino inflado a más, como Dostoievsky, que pretende que lo sabe todo y lo ve todo y nos repite diálogos enteros como si los hubiera grabado con grabadora $\mathrm{y}$ nos cuenta, con palabras claras, cuanto pasa por la confusa cabeza de Raskolnikof como si estuviera metido en ella o dispusiera de un lector de pensamientos, o como si fuera ubicuo y omnisciente como Dios. Y no. No existe el lector de pensamientos, ni Dios tampoco. [...] ¡Al diablo con Dostoievsky, Balzac, Flaubert, Eça de Queiroz, Julio Verne, Cronin, Zola, Blasco Ibáñez y todos, todos, todos los narradores omniscientes de todas las dañinas novelas de tercera persona que tanto mal les han hecho a los zafios llenándoles de humo los aposentos vacíos de sus cabezas! ¡Novelitas de tercera persona a mí, narradorcitos omniscientes! (2013d, pp. 87-88)
El antioqueño rechaza a estos autores porque su literatura es artificiosa, y contraría la realidad al emplear un punto de vista heterodiegético que viola la intimidad de sus personajes al penetrar sus pensamientos. En oposición a esto, Vallejo emplea una perspectiva autodiegética ${ }^{5}$ para dar cuenta de sus recuerdos (primer ciclo narrativo), de sus experiencias presentes (segundo ciclo) o de la mezcla de ambos (tercer ciclo), y para, desde sus limitaciones narrativas, nombrar el mundo: "Que cada quien hable por sí mismo, en nombre propio, y diga lo que tenga que decir» (2013d, p. 42).

Esta poética ha llevado a la crítica a problematizar el género al que pertenecen las novelas del antioqueño. De ahí que se las vea como autorrepresentaciones (Forero, 2011, p. 16), puestas en escena que difuminan los límites de la autobiografía (Fonseca, 2004, p. 13; Montoya, 2007, p. 21), libros que establecen un pacto ambiguo con el lector (Villena, 2009, p. 33; Joset, 2010, p. 124), autobiografías imaginadas (Murillo, 1999, p. 10) o tex-

4 En este artículo, Vallejo, además de reescribir el comienzo de Cien años de soledad para despotricar de lo mal prosista que, según él, es Gabriel García Márquez, aprovecha para de manera irónica pedirle que le enseñe «a ser autor omnisciente y a leer los pensamientos» (2013d, p. 300).

5 En Figuras III, Gerard Genette explica que, dependiendo de la relación que el narrador establezca con la historia que refiere, este puede ser heterodiegético u homodiegético. Mientras el primero es ajeno, de manera absoluta, a la diégesis, el segundo se ve representado en ella. A su vez, este último posee dos grados: en el primero el narrador es protagonista de su relato, posee un grado intenso del narrador homodiegético y por eso se le llama autodiegético; en el segundo, el narrador desempeña un papel secundario de observador y testigo de la acción (1989, pp. 299-300). 
tos en donde lo real se confunde con la ficción (Ledesma, 1989) 6 . Para el común de los críticos, la propuesta estética de Vallejo se encuentra a medio camino entre la autobiografía y la ficción novelesca. Por lo anterior, la voluntariedad (yo digo) y la perspectiva discursiva (narrador autodiegético) le permiten al narrador vallejiano hacer de la diégesis un lugar para construir una figuración del yo y un espacio de autorrepresentación; fenómenos que llevan a pensar la escritura vallejiana como una propuesta autoficcional.

Según Diaconu y Ardila, la ambigüedad con que la crítica califica la narrativa de Vallejo es inherente a la autoficción. Para Diaconu (2013), la autoficción media entre la novela y la autobiografía generando un pacto ambiguo entre el lector y el texto, entre el pacto novelesco (verosimilitud) y el autobiográfico (verdad), el cual produce una doble superación: «de los límites de la autobiografía por los límites novelescos -ficcionales-, y de los límites de la novela recurriendo a un discurso no ficcional, el autobiográfico» (p. 50). Para Ardila (2014), la autoficción es una modalidad de la metaficción (p. 109). En ella, el autor se proyecta de manera ficcional en el espacio diegético para construir «una 'referencia ostensiva' entre el autor empírico y el narrador o el autor implícito» (p. 110) y para señalar cómo él se percibe a sí mismo y considera su oficio como escritor. Ambas críticas entienden la autoficción como la construcción textual de un yo narrador que, aunque distinto al autor empírico, comparte elementos de su biografía. Dicha construcción se hace de cara al lector y con el propósito de cuestionar los límites de la autobiografía ("verdad") y de la novela (ficción).

No obstante, pese a que Vallejo configura una poética del yo en su escritura, La Rambla paralela rompe con el esquema de su obra autoficcional y lleva al narrador a "traicionar" sus principios enunciativos. Este libro refiere la participación de Fernando, principal personaje de las doce novelas, en la feria del libro de Barcelona a finales del milenio. En la historia, el hasta ahora narrador autodiegético también llamado «el último gramático de Colombia» (2002, p. 20) o apodado como «el viejo»concibe un narrador homodiegético que hace una semblanza del gramático, le arrebata sus funciones narrativas y testimonia la forma en que sus recorridos por la ciudad condal le evocan a Medellín, su ciudad natal. Este artículo evalúa la particular forma en que se presenta la autoficción en La Rambla. Para lograr dicho objetivo, se analiza el desdoblamiento del narrador en una figura que ahora narra al viejo desde la tercera persona gramatical; y, a partir de este gesto, se examinan los rasgos de la autoficción que presenta esta novela prestando principal atención al espejo como un mecanismo que le permite al biógrafo evaluar los rasgos estilísticos de su biografiado.

\section{Los desdoblamientos del na- rrador autodiegético}

Desde el inicio del segundo ciclo, Fernando, narrador-per-

6 Según Forero (2010), las novelas de Vallejo son una «recreación creativa de la vida del autor, una autorrepresentación en la ficción» (p. 16). Fonseca (2004) señala que El río del tiempo «exemplifies and underscores the approach that Vallejo takes towards the autobiographical genre and at the same time the blurry limits of autobiography» (p. 13). Para Montoya (2007), el autor antioqueño, «en la medida en que va trazando su autobiografía, desbarata las fronteras de los géneros literarios [...] no es novela, ni historia, ni poesía, ni biografía» (p. 21). Villena (2009) considera que «Vallejo difumina en su narrativa lo que son estrictamente sus opiniones con las de su narrador, pasando el pacto narrativo identitario a ser indistintamente ficcional o ambiguo a pesar de que el lector asuma la convergencia entre la fama del autor, el narrador y el protagonista» (p. 33). Joset (2010) piensa que los libros de Vallejo están «regidos por el pacto de lectura ambiguo entre novela y autobiografía» ( $p$. 124). Murillo (1999), prologuista de El río del tiempo, escribe: «Su asunto es evidentemente autobiográfico, aunque ojo, esto es muy distinto a decir que son autobiografías, [...] más que autobiografía lo que hay ahí es una manipulación y un juego narrativo a partir de una autobiografía imaginada» (p. 10). Margarito Ledesma, crítico creado por Vallejo, comenta que «el autor continúa por lo pronto con su caprichoso recuento de lo vivido y de lo soñado, sin distinguir entre lo uno y lo otro, ni de paso entre lo que son memorias y lo que son novelas, confundiendo los géneros literarios» (Contraportada de Años de indulgencia de la Editorial Planeta de 1989). 
sonaje, desea glosar su propia muerte; el problema narrativo es hacerlo desde la primera persona: «Y yo solo, muriéndome, sin [...] un novelista de tercera persona que atestiguara, que anotara, con papel y pluma de tinta indeleble para la posteridad delirante lo que dije o no dije» (2002, p. 89). Por lo tanto, la estrategia de enunciación empleada por el gramático en los textos previos, no le es suficiente para documentar su final, por ello necesita de una nueva-«un novelista de tercera persona»que documente las palabras de Fernando -«lo que dije o no dije»-. La Rambla paralela es la novela en que Vallejo lleva a cabo este proyecto tanático. En la «Presentación de La Rambla paralela», Vallejo anuncia: «Y sí, me morí en mi ley, en primera persona como viví y escribí, despreciando al novelista omnisciente, ese pobre diablo con ínfulas de Dios Padre Todopoderoso, de sabelotodo» (2013, pp. 287-288). No obstante, cuando el lector se acerca a la lectura de la novela, se encuentra con un narrador que, desde la tercera persona gramatical y con ínfulas de omnisciencia, refiere la vida de otro. ¿Cómo entender, entonces, esta incoherencia patente entre las palabras del autor y la experiencia del lector?

En La Rambla, Vallejo diseña una "maroma literaria" para desdoblar a su otrora narrador autodiegético en las figuras de un suizo y un mexicano, relatores que desde una perspectiva homodiegética refieren el tránsito del viejo al otro mundo $^{8}$. Esta "maroma" posibilita al viejo narrador, por contradictorio que parezca, narrar su propia muerte sin transgredir su arte poética («hablar en nombre propio»). Tras despertarse del sueño en el que llama a Santa Anita, escena con la que inicia esta novela, el viejo se mira al espejo:

En ese instante me desperté $[\ldots][\mathrm{m}] \mathrm{e}$ levanté y $[. .$. fui al baño, $[\ldots]$ y entonces vi en el espejo al hombre que creía que estaba vivo pero no: como le acababan de decir [la persona del sueño que le comenta que Santa Anita y que su abuela ya no existen], en efecto, estaba muerto. [...] El viejo se apoyó en el espejo para no caerse y al hacerlo dejó en él las huellas de los dedos ensuciándolo. Lo que había evitado siempre en vida no fueran a saber después los jueces del futuro por dónde había pasado, siguiéndole la pista de todas sus miserias y todas sus infamias. (2009c, p. 8).

El espejo es el artificio que permite pasar de un relator que describe sus propias experiencias («me levanté», «fui»), «vi») a otro que refiere las acciones de un tercero («se apoyó»,, «dejó», «Lo que había evitado»). El reflejo confirma que el viejo es un muerto en vida que deja huellas susceptibles de ser seguidas por los jueces del futuro (por ese narrador homodiegético). Contrario a los desdoblamientos

$7 \quad$ Fernando Vallejo, en una entrevista con Armando Tejeda (2011), explica la "maroma literaria" como un mecanismo de enunciación que le permite a su narrador desdoblarse para desde la tercera persona decir que ha muerto: "ya llevo escritos tres libros sobre mi muerte, Entre fantasmas, La Rambla paralela y El don de la vida. Tratando de decir yo me morí en primera persona. Tratando de hacer esa maroma literaria, de resolver un problema que me plantea mi obstinación, que soy yo en mi novela, de hablar en nombre propio, con mi voz [...]».

8 Caña (2014) explica que más «que tratarse de un diálogo a dos voces, [...] la conversación mantenida entre ambos personajes es, más bien, el desdoblamiento de la conciencia del viejo quien, segundos antes de morir, participa -como testigo- de los eventos que han conformado su vida. Este posicionamiento le otorga una cierta distancia con respecto a su propia vida de ahí su construcción como narrador externo en contraposición con la involucración interna del viejo protagonista» (p. 217). 
de las novelas previas ${ }^{9}$, en $L a$ Rambla este mecanismo lleva al viejo a constituir un otro que permanece y que convive con él a lo largo del texto. A partir de esta escena inicial, el punto de vista de la novela alterna entre un narrador autodiegético (el viejo) y uno homodiegético que documenta el tránsito del gramático por Barcelona y su periplo hacia la muerte. Gracias al reflejo en el espejo, el viejo construye un sujeto independiente a él; su doble ${ }^{10}$.

Este doble también es una figura particular por cuanto no se contenta con documentar al viejo, sino es un personaje ambivalente. Sentados en el
Café de la Ópera, alguien le pregunta a este otro: « $¿ Y$ usted qué opina?» sobre las palabras del gramático, frente a lo que responde: «Yo nada, soy un biógrafo imparcial que abre y cierra comillas y se atiene a los datos» (p. 120). En principio, esta respuesta muestra dos caminos discursivos diferentes: mientras el viejo ha optado por la autobiografía, el otro lo ha hecho por la biografía, por eso está tras sus huellas. Pero, seguido de lo anterior, la pregunta que le hacen al biógrafo es inquietante porque implica una tercera voz, la cual se presenta como un suizo que escribe en español: «Le hablaba de "vos" [al gramático] como antioqueño por seguirle la corriente. Pero yo antioqueño no soy, Dios libre y guarde. Soy suizo. Un suizo que escribe en español» (Vallejo, 2009c, p. 54). Por lo tanto, La Rambla presenta un narrador homodiegético ambivalente: el biógrafo de origen mexicano y el comentarista, de origen suizo, del biógrafo; ambas personalidades manan del espejo, dialogan con el viejo y no se contentan, en el transcurso de la narración, con ser lacayas de los pasos o palabras del gramático, sino que se convierten en figuras independientes ${ }^{11}$. Por ello, la novela posee un juego especular en donde Fernando, el suizo y el mexicano, se reflejan de manera recíproca ${ }^{12}$.

$9 \quad$ El primer desdoblamiento narrativo se presenta en Entre fantasmas (Vallejo, 2009b, pp. 226-227), última novela de la pentalogía. En este, Fernando personaje se despide del narrador. Tras la separación, el viejo retorna a la ciudad y el escritor termina con sus funciones narrativas y asciende hacia la bóveda de la Catedral de Medellín rumbo al cielo. Este adiós marca el final del primer ciclo y abre el camino a un nuevo comienzo en donde el viejo ahora es el relator de sus vivencias. En $L a$ Virgen de los sicarios, el viejo gramático se desdobla en un narrador omnisciente, en "el hombre invisible" para acceder a la morgue y poder describir el cuerpo muerto de Wílmar, su amante (pp. 117-120). Por último, en El desbarrancadero, al Fernando contemplarse al espejo se desdobla en su imagen reflejo para que esta le administre a su padre, quien se encuentra moribundo, el eutanal con el que podrá morir tranquilo (Vallejo, 2008a, pp. 124-127). Como se puede ver, en los tres casos previos, los desdoblamientos se asocian con el acto de narrar la muerte: la propia en Entre Fantasmas, la de su amante en La Virgen y la de su padre en El desbarrancadero.

10 Sánchez (2016), al estudiar las diferentes figuras del doble en los cuentos de Germán Espinosa, usa como referente teórico a Lubomír Doležel para explicar los tres modos por medio del cual la figura del otro cobra vida: a) por fusión; b) por fisión y c) por metamorfosis (p. 105). Según Doležel (1995), por medio de la fusión dos individuos originalmente separados convergen en el doble, mientras que en la fisión un individuo originalmente simple se fragmenta en dos y en la metamorfosis el doble surge por un proceso de transformación (pp. 97-98). Según esta tipificación estudiada por Sánchez, a partir de Doležel, la manera en que el doble del espejo, en La Rambla, cobra vida, es mediante la fisión.

11 La imagen de este otro, en su función de biógrafo, evoca la del narrador de las tres biografías escritas por Fernando Vallejo: El mensajero (1991) sobre el poeta Porfirio Barba Jacob (1883-1942), Almas en pena, chapolas negras (1995) sobre el poeta José Asunción Silva (1865-1896) y El cuervo blanco (2012) sobre el gramático Rufino José Cuervo (1844-1911). Lo común de estos tres libros es que desafían el género, pues no se concentran en referir la vida de Barba Jacob, Silva o Cuervo, sino se enfocan en mostrar cómo el biógrafo construye la imagen de sus biografiados; motivo por el que el narrador no se contenta con estar al margen del texto (emplear la tercera persona), sino que busca mostrarse en todo momento (a través de la primera persona), semejante a como ocurre en La Rambla paralela.

12 Este juego de narradores que se desdoblan y en donde cada uno es proyección del otro semejan los versos de José Asunción Silva del "Nocturno III": "iy eran una sola sombra larga!». En La Rambla esta imagen de la sombra se menciona en dos ocasiones: «lba solo bajo el sol rabioso por un malecón vacío, seguido por su sombra» (2009c, p. 33) y «Y ahí iba el viejo perdido en su mundo interior, bajo el sol poniente, dejando atrás su larga sombra» (2009c, p. 55). Esta sombra que acompaña al gramático bien puede ser la del biógrafo o la del suizo. En cualquiera de los dos casos lo importante es señalar que ellos se conciben a sí mismos como proyecciones del viejo, como encarnaciones de esa pluralidad ficticia de la que habla el narrador-autor de la pentalogía: "y aquí estoy, aquí estamos, recordando, y hablando a ratos, padre, en pluralidad ficticia» (Vallejo, 2009b, p. 190). 
Esta alternancia narrativa ha suscitado posiciones contrarias en la crítica vallejiana. Salamanca (2013a) comenta que «Vallejo liquida ante nuestros propios ojos su tradicional narrador intradiegético a la vez que le da vida a otro, esta vez extradiegético, que muy campante toma las riendas de la narración apenas ha iniciado la obra» (p. 322). Para este crítico, el cambio se da principalmente para narrar la muerte del viejo gramático, para «deshacerse también de su álter ego, el iconoclasta e injurioso narrador de todas sus obras. La obra se convierte así en una especie de crimen o suicidio literario» (p. 322). Por su parte, Murillo (2013) piensa que el narrador de La Rambla «se desgaja en dos voces paralelas: una en primera persona, a la que ya nos tiene acostumbrados, $\mathrm{y}$ otra en tercera persona que, si bien pareciera inaugurar un narrador omnisciente, algo absolutamente improbable en un narrador como Vallejo, lo único que hace es dar otra perspectiva a la voz y a la mirada» (p. 208). Para Forero (2011), «[e]ste cambio formal implica un punto de quiebre radical en la narrativa de Vallejo, debido a la fidelidad que el autor había guardado por la primera persona» ( $p$. 105). Tal ruptura lleva a que «el narrador utilizado por Vallejo se un[a] a la línea de aquellos usados por Balzac, Flaubert o García Márquez, a quienes tanto había atacado anteriormente» (p. 105). Por ello, esta contra- dicción es un acto del narrador de hacer burla de sus críticos (p. 106) y se debe a un cambio de mentalidad en la que el gramático ya no cree en nada (p. 107).

Salamanca, más allá de considerar el porqué del cambio de perspectiva narrativa, no advierte la contradicción que ella supone en la obra de Fernando Vallejo. Murillo sí lo hace, pero no aclara el porqué de esa nueva voz «pareciera inaugurar un narrador omnisciente», ni explica por qué dicho cambio es «absolutamente improbable», ni esclarece por qué el viejo gramático opta por esta estrategia discursiva, ni demuestra cómo le da otra perspectiva al narrador-autor del primer ciclo o al narrador de las dos primeras novelas del segundo ciclo. Forero refiere la incoherencia y la supuesta traición a los principios narrativos establecidos por el autor antioqueño y, aunque comenta los intereses del gramático de mofarse de los críticos y su cambio de mentalidad, no valora las razones estilísticas por las que el viejo narrador se transforma en un biógrafo o un comentarista. Pese a que La Rambla presenta una mutación en el registro de la enunciación -de la primera persona se pasa a la tercera-, ello no conlleva necesariamente al empleo de un narrador omnisciente, motivo por el que esa supuesta contradicción de la que habla Forero se pone en duda.
Lo llamativo de las oscilaciones narrativas de La Rambla es que, en tanto parten de un protagonista que se desdobla, aún siguen el principio de hablar en nombre propio, puesto que el biógrafo y el comentarista dan cuenta de lo que saben del gramático, y si en ocasiones ingresan a la mente de este para señalarle al lector lo que piensa o cree, es porque comparten una misma esencia narrativa: son uno y el mismo; son una "maroma literaria". Los tres son narradores homodiegéticos, lo que los diferencia es que uno es protagonista de su propia historia (Fernando), mientras los otros tienen un papel secundario al ser testigos de la vida del gramático (el biógrafo y el comentarista). Por lo tanto, parafraseando las palabras de Vallejo sobre El Quijote, La Rambla no es una novela de un narrador que juega a la omnisciencia, sino una parodia de la tercera persona por medio del empleo de la primera, una novela en la que el viejo se burla del alcance del narrador omnisciente y de la forma en que este lee los pensamientos de sus personajes.

Por otro lado, por más que hay un cambio de registro que emplea la tercera persona gramatical para juzgar, interpolar y confrontar al viejo gramático, ello no quiere decir que el narrador sea omnisciente. Genette explica que «[1]a elección del novelista no es entre dos formas gramaticales, sino entre 
dos actitudes narrativas (cuyas formas gramaticales no son sino una consecuencia mecánica): hacer contar la historia por uno de sus «personajes» o por un narrador extraño a dicha historia» (1989, p. 298). En La Rambla, el gramático, el suizo y el mexicano hacen parte del universo diegético, mientras que Dostoievsky o Dios, como relatores, están por fuera de este. El viejo, el biógrafo y el comentarista siempre cuentan de manera subjetiva su presente o sus recuerdos, sin importar el empleo de verbos en primera o en tercera persona. Por lo anterior, dado que las figuras del suizo y del mexicano emanan del gramático y son sus dobles, más que personajes independientes, son un mismo sujeto con tres rostros distintos. Por esto, Musitano (2012) sugiere que La Rambla «está construida a partir de un diálogo consigo mismo» (p. 4) y Richey (2015) la caracteriza como «a hallucinatory extracorporeal chronicle of the narrator's own death» (p. 270).

Este cambio constante de una perspectiva autodiegética a una homodiegética, que por momentos posee una focalización fija -lo que se refiere está restringido por el protagonista de la historia- y en ocasiones una variable -la voz narrativa pasa de un personaje a otro-, y que funge como narrador-protagonista (Fernando) y a la vez como narrador-testigo del protagonista, permite ver el interés del autor de oxigenar su discurso narrativo. Por lo general, la crítica ha calificado la obra de Vallejo como redundante (González, 2015, p. 195), recapitulativa (Giraldo, 2006, p. 113), que retorna siempre a lo mismo (Castrillón, 2010, p. 16), cantaletosa (Montoya, 2007, p. 19), o reiterada (Rey, 2013, p. 25) ${ }^{13}$. Para la crítica, la obra de Vallejo tiene una monotonía temática la infancia en Medellín del protagonista, sus recuerdos de Santa Anita y su abuela materna- y una voz narrativa recalcitrante que, además del empleo de la primera persona, se caracteriza por despotricar de Colombia, la mujer y la religión. En el segundo ciclo, el viejo, en su función de narrador, se encuentra agotado por emplear la misma postura narrativa de la pentalogía -narrador autodiegético-. Para salir de este agobio, se desdobla en un narrador homodiegético de aspecto dual (suizo-mexicano) para contar su tránsito hacia la muerte ${ }^{14}$. Si bien el viejo es el protagonista, contrario a lo hasta ahora escrito, este no es quien describe su paso por el mundo; el encargado de hacerlo es el biógrafo-comentarista. En este sentido, cederle la voz a un otro para que lo narre implica que el viejo se marginaliza, pues ya no tiene las riendas del relato, y la imagen que él mismo ha construido de sí ahora está en manos de otro. La narración entonces pasa de un narrador-protagonista a tener un narrador, por un lado; y un protagonista, por el otro.

\section{El espejo de la autoficción}

A partir del análisis que Alberca y Navarro (2007) hacen de la autoficción en España, se puede entender la forma en que el espejo hace de La Rambla una novela autoficcional.

Los relatos autoficticios se caracterizan por una minuciosa observación de

13 Para González (2015), la redundancia de Vallejo «abarca tanto la repetición como el exceso con que se ha caracterizado su obra» (p. 195), y permite la supervivencia del contenido temático. Giraldo (2006) habla de las novelas de El río del tiempo como textos que "giran en redondo», como novelas de recapitulación, en donde lo descrito antes es susceptible de volver a ser contado (p. 113). Castrillón (2010) comenta que en la pentalogía hay «anécdotas que se relatan constantemente, en una suerte de retorno a lo mismo que se transforma y recrea cada vez que se narra» (p. 16). Montoya (2007) explica que el discurso vallejiano es cantaletoso: «de tanto repetirse y acudir a la invectiva atragantada se convierte en una verbosidad agresiva que hace reír [...] [y que] se torna fatigante monotonía» (p. 19). Por último, Rey (2013) habla de la prosa de Vallejo como un «eterno monólogo» (p. 25) que le da ritmo a la narración de cada una de sus novelas.

14 Esta búsqueda por airear los modos narrativos lleva al gramático a hacerse al margen para escribir la crónica de Carlos, su hermano, en Mi hermano el alcalde, en la cual retoma las estrategias discursivas de las biografías (mostrar documentos, señalar la manera en que los obtiene, dar cuenta de la forma en que los lee y los complementa con otros), para no contravenir el principio creativo de hablar en nombre propio. 
un sujeto insignificante, en ocasiones megalómano, pero sin tragedia ni grandeza, con una calculada imposibilidad para discernir lo verdadero de lo que no lo es y por la mezcla indisoluble de lo real y lo ficticio. [...] La autoficción mantiene, por un lado, una evidente, pero engañosa, relación con la autobiografía y las memorias, y, por otro, una vecindad cómoda con las novelas [...]. Esta confusa y tensa relación permite considerar este tipo de relatos como el espacio [...] de la manifestación de dos síntomas característicos de nuestra época: el contradictorio afán de desaparición y afirmación del sujeto y la conflictiva relación entre lo real y su representación. (pp. 269-270).

Según estas palabras, los textos autoficticios refractan al sujeto que los enuncia y se sustentan en tres características: 1. desdibujan los límites entre lo real y lo ficticio; 2. desvanecen las fronteras genéricas de la autobiografía y la novela, siendo una mezcla de ambas y produciendo, en palabras de Souquet (2014), una "mezcla oximorónica" entre el pacto de lectura autobiográfico y el pacto novelesco (p. 260); y 3. a la par que afirman al sujeto también lo hacen desaparecer. Estas tres propiedades de la autoficción están presentes en La Rambla.

El desvanecimiento de los límites entre lo ficticio y lo real se da por medio del espejo, pues de este emergen las figuras del mexicano y del suizo. Además, La Rambla presenta un relato enmarcado, pues el sueño sobre Santa Anita encuadra la experiencia de insomnio del gramático en Barcelona, lo que posibilita leer la novela como un relato circular $^{15}$, razón por la que se podría plantear que el viejo no abandona el cuarto de hotel y se contenta con describir lo que ve en la superficie del cristal, es decir, la vida de ese biógrafo y comentarista que desde el otro lado, a la vez, glosan a la figura del gramático que produce el reflejo. A lo anterior, se suma que los vagabundeos del gramático por la ciudad Condal están mediados por el jet-lag que padece, fruto de su viaje en avión desde ciudad de México, y por su incapacidad de conciliar el sueño durante los cinco días que permanece en la capital catalana. Debido a esto, el viejo desvaría $\mathrm{y}$, por eso, cree ver fantasmas transitar por la Rambla. Así mismo, al confeccionar por medio del espejo a un otro plural para hablar de él, La Rambla juega con los géneros de las memorias, la que hacen el mexicano y el suizo del tránsito de Fernando por la ciudad condal, y de la novela, la que fabula el viejo al reseñar sus visiones en el espejo. Esta ambigüedad genérica, por un lado, afirma al yo narrador de las novelas previas a $L a$ Rambla, puesto que desde su experiencia de observación narra el mundo tras el espejo; pero, por el otro lado, niega su condición de sujeto, pues él ya no es él, sino se convierte en biógrafo y comentarista.

A su vez, en palabras de Ardila (2014), en La Rambla, Vallejo se vale de comentarios explícitos «para configurar un personaje ambivalente que señala de manera ostensiva hacia el autor empírico y simultáneamente escamotea tal identidad» (p. 157). Estos comentarios construyen relaciones autotextuales que generan un efecto de referencia acumulado producto de la

\footnotetext{
15 Pese a lo fragmentario del discurso, La Rambla paralela inicia con el sueño en el que el viejo llama a Santa Anita (pp. 7-8), sueño que se reescribe al final de la novela (pp. 162-163), desde un hotel en Barcelona (pp. 9, 148). Una vez se despierta se mira al espejo (pp. 8, 61-62, 75, 82, 97, 103, 161) y después sale a caminar por la ciudad condal (p. 9) y cuenta cómo llegó a la capital catalana en un vuelo procedente de México D.F. (10-12). Yendo por la Rambla se detiene en el Café de la Ópera (pp. 10, 24, 47, 61, 74, 76, 150, 180) a contemplar la gente caminando (pp. 23, 42, 61, 85, 144), ingerir alcohol —cada vez que lo hace pide un licor diferente- y en ocasiones a departir con el narrador homodiegético, con los demás asistentes a la feria o simplemente con él mismo. Desde el café recuerda cómo cuando era joven, caminando por la Rambla, conoció a un muchacho con el que se fue a un hotel en la calle Paralelo (pp. 17-18, 43-44, 111-112, 114-115, 116, 138). Así mismo, la Rambla le evoca a Junín, calle del centro de Medellín (pp. 14, 83, 151), y en ella el narrador homodiegético registra que el viejo se desvanece y muere (pp. 9, 110, 119, 127, 159).
} 
reiteración (p. 163). De ahí, la omnipresencia en la obra de Vallejo de sus espacios topofíli$\cos ^{16}$ (la Medellín de su infancia y Santa Anita), de sus padres (Aníbal Vallejo y Lía Rendón), de su abuela (Raquel Pizano), de sus hermanos (Darío, Carlos, Silvio, Gloria...), de su perra llamada Bruja, de las mismas anécdotas (El globo navideño, la manera como conduce el abuelo, las escenas de los decapitados bajando por el río), de un estilo discursivo (la perorata), del hecho de autonombrarse como el autor colombiano que más vende en la feria del libro de Barcelona (Vallejo, 2009c, pp. 21, 27, 64, 70, 86) e, incluso, de parafrasear el primer libro de la pentalogía, Los días azules (2009c, p. 44). Las palabras de Ardila (2014) refuerzan la idea expuesta por Alberca y Navarro, pues a la par que Vallejo intenta dar una imagen de sí en la novela, sus palabras hacen desaparecer dicha relación identitaria; por ello, «el autor [Vallejo] se representa a sí mismo de una forma híbrida, esto es, acudiendo a datos referencialmente verdaderos, de naturaleza ostensiva, e inventando otros, ficcionales entonces» (pp. 138-139).

Estos comentarios autorreferenciales, a la vez, hacen que ese rostro dual que germina en la superficie del cristal, por momentos, se confunda con la imagen del viejo. Es llamativo lo mucho que se parecen, a tal punto que Musitano (2012) señala que «Vallejo [en La Rambla] abre varias dimensiones en el relato para jugar a confundir al lector, para que no sepamos quién nos habla» (p. 4). La figura dual del narrador homodiegético demuestra, de manera constante, el profundo conocimiento que tiene sobre el viejo (2009c, p. 84), se acerca a la manera de pensar de este frente a Colombia o la reproducción $\mathrm{y}$, además, emplea los mismos recursos de enunciación: ambos se limitan a referir lo que saben o bien porque lo vieron o bien porque se enteraron de ello; ambos se autocorrigen (2009c, p. 59) y tienen un flujo narrativo en que concatenan escenas sin un aparente vínculo; a ambos se les olvida el hilo del discurso (2009c, p. 128), son repetitivos y contradictorios a la hora de narrar las mismas escenas, e incluso, por momentos, se atreven a señalar lo que sus personajes piensan o sienten. Y, por si fuera poco, el suizo remeda la manera antioqueña de hablar del viejo "Le hablaba de "vos"» (2009c, p. 54) y el biógrafo emula el tono discursivo de sus peroratas; razones por las que sus voces llegan a confundirse. Por ello, las voces del viejo, el suizo y el mexicano, están en un juego constante y tensionante, puesto que por momentos armonizan, dado que es difícil reconocer una identidad detrás de las palabras porque la voz del viejo resuena en las de sus imágenes reflejo, y por momentos producen sonidos discordantes, ya que tanto el biógrafo como el comentarista procuran adquirir una manera de hablar propia y a través de nombrarse a sí mismos perfilarse como sujetos independientes.

A pesar de estas equivalencias, en tanto que el espejo media la relación entre el viejo y su biógrafo-comentarista, son dos los sujetos: Fernando y su imagen reflejo. Al estar del otro lado del cristal, el biógrafo y el comentarista consolidan personalidades autónomas que se escinden por completo de la figura de la cual nacen. Al menos, así lo entiende Richey (2015) cuando determina que la novela establece una voz dual que surge de los fragmentos de un mismo fantasma y que gracias al espejo «el viejo looks at and from himself at once» (p. 276). Según Richey, el espejo le permite al viejo crear una segunda voz que «offers him the perspective to see multiple

16 En La poética del espacio, Bachelard estudia la relación del ser humano con lugares habitacionales (el cuarto, el sótano, el ático...) para explicar cómo dichos recintos se convierten en espacios topofílicos; es decir uespacios ensalzados [a los que su] valor de protección que puede ser positivo, se adhieren también valores imaginados, y dichos valores son muy pronto valores dominantes. El espacio captado por la imaginación [...] [e]s vivido. Y es vivido, no en su positividad, sino con todas las parcialidades de la imaginación» (2002, p. 28). 
layers of himself at once» (pp. 277-278). Es decir, el cristal es el artilugio que le faculta al viejo a comprender sus múltiples facetas y dimensiones. Por esto, el espejo no solo produce un reflejo, sino, quizá lo más importante, es que este se convierte en la herramienta que le permite al narrador evaluar los rasgos estilísticos del gramático. Así, por ejemplo, este último señala que el viejo desvaría (2009c, p. 15) o que tenía la costumbre «de hablar [...] como un loco» (2009c, p. 23) o de sostener un «diálogo de sordos consigo mismo» ( $p$. 40). Comentarios aislados que construyen una autorreferencialidad ${ }^{17}$ a lo largo de la obra y que permiten entender las características del proceder narrativo del viejo gramático, no solo en esta novela sino también en las once restantes. El biógrafo señala cómo Fernando al caminar por la Rambla «[i]ba diciéndose lo de siempre, tocando su viejo disco rayado. Que lo uno, que lo otro, que lo otro. Que los pobres reproduciéndose como conejos, los políticos robando [...] El camino más trillado dándoselas de original» (2009c, p. 62). Este conocimiento de los rasgos estilísticos de la narra- tiva de Fernando, le permite al narrador homodiegético esgrimir un arte poética del quehacer como escritor del viejo que se sustenta en el empleo reiterado de formas y contenidos: "Al fin de cuentas es lo que hacía desde hacía años: pasar unos míseros recuerdos hechos de cambiantes palabras a un deleznable papel» (2009c, p. 158). Los lineamientos que establece el narrador con su comentario, son cuatro: una acción prolongada en el tiempo (la escritura), que emplea un material narrativo (los recuerdos), los cuales saca de un lado para meterlos a otro («pasar unos míseros recuerdos») y a la hora de transvasarlos lo hace con «cambiantes palabras». De esta manera, en el primer ciclo narrativo, el gramático configura unos recuerdos que son susceptibles de volver a aparecer en el segundo y el tercer ciclo. Sin embargo, cada vez que se rememora la escena el narrador traslada su contenido de novela en novela, y al hacerlo transforma la manera en que es enunciada. Al proceder de esta forma, el nuevo recuento de una anécdota pasada no anula al anterior sino que convive con ella retroalimentándolo.
Pero pese a que La Rambla cumple con los criterios establecidos por Alberca y Navarro (2007) -textos que al refractar al sujeto enunciativo desdibujan los límites entre lo real y lo ficticio, que mezclan la autobiografía con la novela y donde el sujeto se afirma en el discurso a la par que desaparece en él-, incumple con el principio fundacional que, para estos críticos españoles, debe ostentar la autoficción: «una autoficción es una novela o relato que se presenta como ficticio, cuyo narrador y protagonista tienen el mismo nombre que el autor» (p. 158), y por ello «Su transparencia autobiográfica proviene de la identidad nominal, explícita o implícita, del narrador y/o protagonista con el autor de la obra, cuya firma preside la portada» (p. 128). Según estos críticos, es necesario que la autoficción construya una identidad nominal tácita o explícita entre el autor, el narrador y el personaje y se presente por medio del empleo de una perspectiva autodiegética, cosa que no ocurre en la novela de Vallejo. La autoficción en La Rambla es particular, por cuanto no construye una imagen de autor empleando la primera persona

17 Ardila (2014), en El segundo grado de la ficción, analiza tres movimientos referenciales que permiten el surgimiento de la metaficción: la autoconciencia, la autorreflexividad y la autorreferencia. Frente a esta última, la crítica antioqueña señala que es una tarea que debe llevar a cabo el lector y que ésta consiste en entender cómo, en la misma obra, cobran vida elementos de valor referencial que se deben poner en diálogo: «En el texto metaficcional sucede que desde el interior mismo de la obra, por mediación del comentario explícito y directo, se llama la atención del lector no solo sobre la relevancia del contenido expreso en dichos comentarios, sino también sobre la necesidad de atenderlos, de rastrearlos uno a uno para reconfigurar aquello que se presenta de manera dispersa y fragmentada de un comentario a otro» (p. 127). Al seguir estas pistas, el lector se convierte en un personaje activo que participa, por medio de la interpretación de estas referencias, en la creación de la obra. 
gramatical (una voz que dice yo), sino la tercera.

Casas (2012) explica este fenómeno, no como algo que contradice los presupuestos de la autoficción, sino como un fenómeno que incluso los afirma. Para esta autora, la autoficción no surge simplemente al establecer un pacto referencial con la figura autorial, ya que es posible que la novela problematice la identidad nominal entre autor-narrador-personaje -tal como sugiere Alberca y Navarro que es un pilar de la autoficción- mediante el empleo de múltiples modalidades del nombre (p. 36), es decir que al sujeto se le apele de distintas formas a lo largo del texto -como ocurre con el viejo a quien apodan maestro, el antioqueño, el gramático, el autor que más vende...- $\mathrm{o}$ incluso con transgresiones de la perspectiva narrativa en donde una voz autodiegética puede llegar a devenir en una heterodiegética en la que, por un lado, el narrador se asume como un sujeto incapaz de penetrar en los pensamientos de sus personajes; $y$, en otros momentos, mostrar la intimidad de estos (p. 37). Alternancia que se muestra incoherente toda vez que, por lo menos en el caso de La Rambla, el narrador se muestra como un ser que se limita a abrir y cerrar comillas (Vallejo, 2003c); $\mathrm{y}$, por otros momentos, es capaz de acceder a su intimidad. Al ocurrir esto, como lo explica Casas (1989) apoyándose en Genette, surge la paralepsis, es decir aquella transgresión en la que se da más información de la que autoriza el código de focalización, gracias a que el narrador incursiona en la conciencia de un personaje a lo largo de un relato generalmente regido por focalización externa (p. 249).

El camino andado en este artículo permite ver que el espejo no solo es un objeto accesorio en la narración de La Rambla paralela, sino que es el mecanismo que le permite al narrador de la pentalogía y de $L a$ Virgen y El desbarrancadero desdoblarse en una figura dual (Biógrafo-comentarista) que ahora documenta al viejo por medio del empleo de un nuevo mecanismo de enunciación: el narrador homodiegético. Estrategia que, a la vez, permite crear una tercera persona que reemplaza al pronombre yo enmascarándolo en un él, pero que sigue siendo él. Además, este artificio le imprime nuevos aires a un discurso que, como el mismo biógrafo califica, es un «disco rayado» (Vallejo, 2009c, p. 63). Así mismo, la imagen reflejada en el cristal le posibilita al texto mirarse a sí mismo para entender tanto el proceder discursivo de esta novela como el de los tres ciclos narrativos: una narrativa de palabras cambiantes.

\section{Referencias}

Alberca, M., \& Navarro, J. (2007). El pacto ambiguo: de la novela autobiográfica a la Autoficción. Madrid: Digitalia.

Ardila Jaramillo, A. C. (2014). El segundo grado de la ficción. Medellín: Fondo Editorial EAFIT.

Bachelard, G. ([1957] 2002). La poética del espacio. (E. de Champourcine, Trad.). México D.F.: Fondo de Cultura Económico. 
Caña, M. del C. (2014). Cartografías del ser, la ciudad y la nación: violencias en La Rambla paralela. Cincinnati Romance Review, (38), 216-231.

Casas, A. (comp.) (2012). Introducción. El simulacro del yo: la autoficción en la narrativa actual. En: $L a$ autoficción. Reflexiones teóricas (pp. 9-42). Madrid: Arco/Libros.

Castrillón Castrillón, A. A. (2010). La temporalidad en Martin Heidegger y El río del tiempo de Fernando Vallejo. (Tesis de Maestría). Universidad de Antioquia, Antioquia, Colombia.

Diaconu, D. (2013). Fernando Vallejo y la autoficción. Coordenadas de un nuevo género narrativo. Bogotá: Universidad Nacional de Colombia.

Doležel, L. (1995). A Semantic for Thematic: the Case of the Double. En: C. Bremond, J. Landy, y T. G. Pavel (Eds.), Thematics: New Approaches (pp. 89-102). Albany: State University of New York Press.

Domínguez Torres, M. A. (2016). El espacio en Fernando Vallejo. Una aproximación literaria al universo diegético, rural y urbano de su narrativa autoficcional. (Tesis doctoral). Universidad de los Andes, Bogotá, Colombia.

Fonseca, A. (2004). Against the world against the life. The Use and Abuse of the Autobiographical genre in the works of Fernando Vallejo. (Master Thesis). Virginia Politechnic Institute, Virginia, EE.UU.

Forero Gómez, A. F. (2011). Crítica y nostalgia en la narrativa de Fernando Vallejo: una forma de afrontar la crisis de la modernidad. (Tesis doctoral). University of Iowa, Iowa, EE.UU.

Genette, G. ([1972] 1989). Figuras III (C. Manzano, Trad.). Barcelona: Editorial Lumen.

Giraldo, L. M. (2006). Fernando Vallejo: piensa mal y acertarás. Cuadernos de Literatura, 11(21), 104118. Bogotá: Pontificia Universidad Javeriana.

González, J. C. (2015). Vallejo, Vargas Vila: oposición, redundancia. Cuadernos de Literatura, 19(37), 185-203. Bogotá: Pontificia Universidad Javeriana.

Joset, J. (2010). La muerte y la gramática: los derroteros de Fernando Vallejo. Bogotá: Taurus.

Montoya, P. (2007). Fernando Vallejo: demoliciones de un reaccionario. América, (54), 18-27.

Murillo, J. H. (1999). Prólogo. En: El río del tiempo (pp. 7-16). Bogotá: Editorial Alfaguara.

Murillo, J. H. (2013). El paso del insomne. En: L. M. Giraldo y N. Salamanca (eds.), Fernando Vallejo. Hablar en nombre propio (pp. 203-213). Bogotá: Editorial Pontificia Universidad Javeriana \& Universidad Nacional de Colombia. 
Musitano, J. (2012). Detrás de una máscara fantasmagórica: una lectura de La Rambla paralela de Fernando Vallejo. Orbis Tertius, 17(18).

Rey, M. (2013). En los frágiles, coloridos, volátiles globos colombianos de Fernando Vallejo: una constante e intensa evocación. En: L. M. Giraldo y N. Salamanca (eds.), Fernando Vallejo. Hablar en nombre propio (pp. 25-36). Bogotá: Editorial Pontificia Universidad Javeriana \& Universidad Nacional de Colombia.

Richey, M. (2015). Two-Way Mirror: The Two Voices of Exile in La Rambla paralela by Fernando Va1lejo. Cincinnati Romance Review, 39, 269-284.

Salamanca-León, N. (2013a). Escritura y exilio en La Rambla paralela. En: L. M. Giraldo y N. Salamanca (eds.), Fernando Vallejo. Hablar en nombre propio (pp. 321-328). Bogotá: Editorial Pontificia Universidad Javeriana \& Universidad Nacional de Colombia.

Salamanca-León, N. (2013b). Pater familias paradiso expulsus. En: L. M. Giraldo \& N. Salamanca-León, N. (eds.), Fernando Vallejo. Hablar en nombre propio (pp. 161-190). Bogotá: Editorial Pontificia Universidad Javeriana \& Universidad Nacional de Colombia.

Sánchez, N. (2016). Desdoblamiento como eje composicional en los cuentos de Germán Espinosa. La Palabra, (29), 103-115. doi: https://doi.org/10.19053/01218530.n29.2016.5704

Souquet, L. (2014). Una autoficción «espectacular»: Pedro Lemebel y Fernando Vallejo (S. Arroyo Redondo, Trad.). En: A. Casas (eds.), El yo fabulado. Nuevas aproximaciones críticas a la autoficción (pp. 247-267). Madrid: Iberoamericana / Vervuert.

Tejeda, A. (2011). Fernando Vallejo y El don de la vida. Babab. Cultura de revista, (2). Recuperado de http://www.babab.com/2011/01/02/fernando-vallejo/

Todorov, T. ([1978] 1991). Los géneros del discurso (J. Romero León, Trad.). Caracas: Monte Ávila Editores Latinoamericana.

Vallejo, F. (1989). Años de indulgencia. Bogotá: Editorial Planeta.

Vallejo, F. (1999). El río del tiempo. Bogotá: Alfaguara.

Vallejo, F. ([1994] 2002). La Virgen de los Sicarios. Bogotá: Alfaguara.

Vallejo, F. ([2001] 2008a). El desbarrancadero. Bogotá: Alfaguara.

Vallejo, F. ([2004] 2008b). Mi hermano el alcalde. Bogotá: Alfaguara.

Vallejo, F. ([1989] 2009a). Años de indulgencia. Bogotá: Alfaguara. 
Vallejo, F. ([1993] 2009b). Entre fantasmas. Bogotá: Alfaguara.

Vallejo, F. ([2002] 2009c). La rambla paralela. Bogotá: Alfaguara.

Vallejo, F. ([1988] 2009d). Los caminos a Roma. Bogotá: Alfaguara.

Vallejo, F. (2010). El don de la vida. Bogotá: Alfaguara.

Vallejo, F. (2013a). Casablanca la bella. Bogotá: Alfaguara.

Vallejo, F. ([1987] 2013b). El fuego secreto. Bogotá: Alfaguara.

Vallejo, F. (2013c). Los días azules. 1985. Bogotá: Alfaguara.

Vallejo, F. (2013d). Peroratas. Bogotá: Alfaguara.

Vallejo, F. (2015). ;Llegaron! Bogotá: Alfaguara.

Villena Garrido, F. (2009). Las máscaras del muerto: autoficción y topografias narrativas en la obra de Fernando Vallejo. Bogotá: Editorial Pontificia Universidad Javeriana. 